\title{
Toward Seamless Environments for Dispute Prevention and Resolution
}

\author{
Davide Carneiro, Paulo Novais, José Neves \\ Department of Informatics \\ University of Minho, Braga, Portugal \\ \{dcarneiro, pjon, jneves\}@di.uminho.pt
}

\begin{abstract}
Given the evolution of the Information Technology society, it is now rather simple to acquire products or services in a foreign country. This practice may conduct to the event of conflicts whenever a consumer detects some fault or malfunction in services or products he/she had bought. A situation that may worsen if at the time of the uncovering of the defect, the shopper is already in a different geographical arena. There is thus the need to develop computational tools that may prevent these disputes from even happening. In this work it is proposed the development of seamless intelligent environments for dispute resolution that will surround the user, independently of his/her location. It is described the implementation of a prototype that may provide contextualized real-time information and legal support to consumers. The objective is to decrease the number of disputes due to a poor understanding in relation to the The Law and make justice more personalized and closer to people.
\end{abstract}

Keywords: Online Dispute Resolution, Mobile Online Dispute Resolution, The Law, Intelligent Environments

\section{Introduction}

The technological developments in the last decades led to undeniable changes in our society, visible in barely all aspects of our daily lives. One of those aspects is the way in which we buy products. While in the past goods or services were bought in person in a relatively small geographical area, it is now possible to buy them from any part of the world. The most common way is to use online stores such as Amazon or eBay, which truly enabled worldwide commercial transactions. On the other hand, it is also possible to travel abroad and acquire those same goods or services in a foreign country. In any way, there is a normal risk on this kind of transactions, i.e., buyers are not always aware of their rights as consumers.

Indeed, problems arise when the product that was bought does not comply either with the seller marketing, lacks some feature, is of poor quality or is even de- 
fective. In such circumstances, the regulations that apply are the rules of the country in which the store is located, and the consumer may be faced with some problems, namely:

(i) Once a buyer acquires an item, generally he/she does it abroad, and normally is not aware of his/her rights as a consumer; and

(ii) When the store does not wish for to settle the affair, and the buyer decides to go into a litigation process.

On the other hand, such processes may have to be conducted in a unfamiliar environment, making it impractical for cut-rate products. If we acknowledge that the majority of online transactions deal with such products, we can estimate the amount of small-value disputes that arise every day and are not worked out because of unsuited legal processes.

Therefore, two main problems may be identified: (1) the buyer is usually unaware of his/her consumer rights; and (2) the buyer has no realistic way of solving an eventual conflict. Ultimately, this may lead to a decrease in the degree of satisfaction of the buyers, influencing in the negative the business-related transactions.

This trend comes with other challenges that face the legal field. Know-how, in general, has significantly increased the amount of disputes, rendering courts slow and ineffective, making access to justice more difficult and thus less fairly. One answer to this problem may came in the form of Alternative Dispute Resolution (ADR), a way of solving disputes out of courts, using alternative processes such as negotiation, mediation or arbitration [1, 2, 3]. Nevertheless, these processes still require the disputant parties to meet in a physical place in order to solve the dispute. The evolution towards Online Dispute Resolution (ODR) is therefore regarded as a natural way [4]. ODR describes a set of methods in which technology is used to implement already traditional forms of ADR, in online environments. In order for ODR to be more than simple negotiation or mediation over a "phone line", artifacts from Artificial Intelligence may have to be considered [5]. The objective is that ODR tools may be able to support disputant parties by actively proposing strategies and solutions, compiling useful information, ultimately making judicial processes more efficient.

However, in order to interact with such ODR tools, parties still need to have access to web-enabled computational platforms. Moreover, these tools are usually only used to solve a dispute. In this work, we look to this problem under a different perspective, namely at a seamless environment for dispute prevention and resolution. The main objective is to build up an environment that may, in principle, to prevent a dispute by providing key information at the time of the purchaser, about its possible negative results, taking into consideration the norms that apply in the present customer scene, i.e., when the buyer actually buys the item, he/she may be aware of the potential future costs in cases of product defect. The secondary objective of this work is to provide mobile access to a previously existing ODR platform, i.e., UMCourt Commerce [6]. UMCourt Commerce is an agent-based [7] ODR platform targeted at the Commercial Law field. Using this online platform, 
an unsatisfied buyer can fill in a complaint and the platform suggests an outcome based on the Portuguese Commercial Law. A detailed description of the platform is provided in [6], including a description of the process model, some use scenarios and the field of law covered, which includes Decree of Law (DL) 67/2003 (as published by DL 84/2008) (Portuguese laws) [8, 9].

In the long term, we want to complement UMCourt with Ambient Intelligence functionalities [12] that may provide even more circumstantial information for the dispute resolution process, including the parties' emotional state. These environments will thus be abstract in essence, in order to provide such information regardless the domain of the dispute. In that sense, this work is being developed in three different legal domains, namely The Labor Law, Property Division and, as mentioned before, The Commercial Law.

\section{Ambient Intelligence for Dispute Resolution}

Among the disadvantages of current ODR tools, one of its major drawbacks is their coolness, i.e., it is easier for parties to lie without the intimidating presence of a judge. Moreover, a very important part of the communication process is lost. Mehrabian [14], states that most of the meaning that we derive from a face-to-face conversation comes from other facets than the words spoken, namely the tone of voice, the loudness, the facial expressions or the body gestures. Indeed, it is our conviction that intelligent environments would allow, at all, that this knowledge is to be acquired and included in the dispute resolution process model, making it richer, fairest, trueness and more effective.

We are currently taking the first steps towards the integration of Ambient Intelligence techniques with ODR platforms, resulting in dispute resolution environments that may support these and other functionalities. At this point, this environment tends to support wireless networks and a mobile device on the client side, holding up on an application server. Following this approach, and considering the Commercial Legal Domain, we want buyers to use the tool with the objective of getting information about their rights and risks as consumers, prior to buying a product or service. In that sense, the prototype developed can be used in two different ways, i.e., it can be used as an interface for the pre-existing platform, or it can be accustomed as a protective information tool. The main objective of the mobile device is to gather as much background information as possible (e.g., current realm, regional settings) in order to make available helpful actions or work for customers. 


\subsection{The Architecture and an Overview of the Environment}

The development of such architecture poses some multifaceted challenges. Indeed, the most palpable one is how to interconnect (remote) software agents with the ones in the environment. In order to address this problem, the architecture adopted was based on two open technologies: OSGi and Jade. The development process followed in order to combine these two technologies to build an intelligent environment is described in [13]. OSGi is a modular approach to software development that relies on the concept of bundle: a bundle is able to provide and use services. It is used to fulfill a main goal, that of creating a consistent layer that will allow any device to be connected with the software layer. This layer is twisted by assigning (at least) one bundle for each appliance (e.g., sensor, personal device). Each bundle is specialized in that appliance, hides its singularities and provides its functionalities in terms of an OSGi service. These functionalities may then be used by any other bundle, without these being specialized on how to use a particular one, i.e., they simply have to request a standard service.

Jade agents [11], on the other hand, are used to implement highlevel behaviors (e.g., rule-based reasoning, case-based reasoning, decision making). Concretely, given the legal domain being focused, agents contain knowledge about the Portuguese Commercial Law, in the form of a set of laws. These agents thus take the information about the case and, depending on the type of the request, evaluate it and return a solution. Agents are tendentiously on the server side.

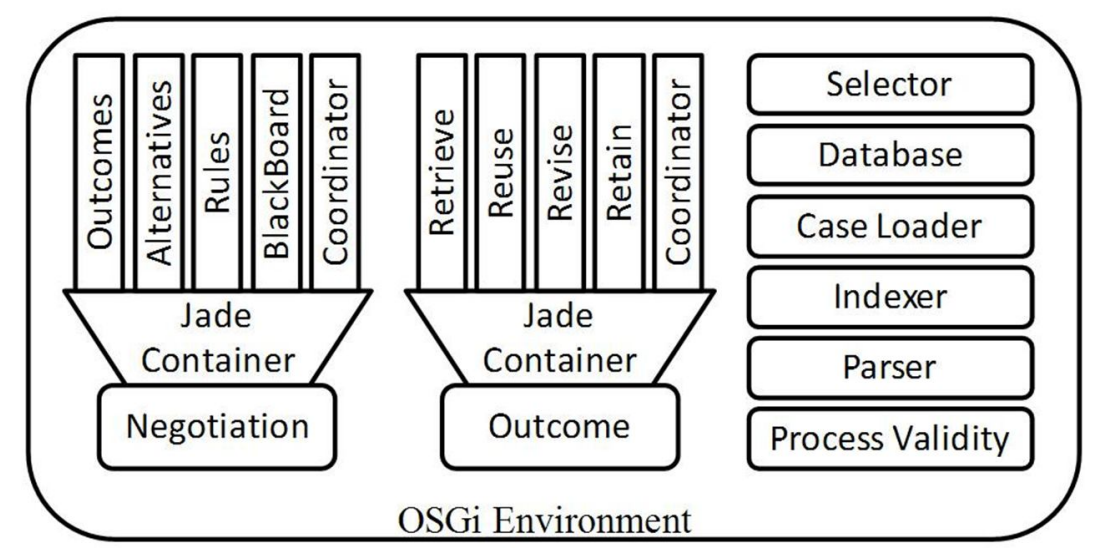

Fig. 1. A simplified view of the architecture. A more detailed description is given in [13].

On the client side, an application was developed to act as an interface between the user and the server. This function allows the user to login or register on the environment (Figure 2). The same login information is used either on the mobile or the web site, creating a seamless information environment. This means that the user may access his/her data (e.g., current case, previous cases, personal infor- 
mation) using a standard web browser, or he/she may access a lighter version of it and particularities on the dispute, under an ODR environment.

Table 1: The system information

\begin{tabular}{|c|c|}
\hline Information & Description \\
\hline Value (new) & The value of the product or service when it was bought \\
\hline Value (used) & The current estimated commercial value of the product or service \\
\hline Type of product & The nature of the product or service (e.g., real estate, mobile, used, new). \\
\hline Date of purchase & $\begin{array}{l}\text { The date under which the product or service was made available to the } \\
\text { customer. }\end{array}$ \\
\hline Date of event & The date under which the defect was detected by the customer. \\
\hline Date of complaint & The date under which the buyer communicates the defect to the seller. \\
\hline Delivery to Supplier & The date under which the product is delivered to the seller, for repair. \\
\hline Temporary $\mathrm{r}$ & $\begin{array}{l}\text { The date under which a similar product or service is made available to } \\
\text { the user to be used as a substitution of the product or service being re- } \\
\text { paired. }\end{array}$ \\
\hline Product return & $\begin{array}{l}\text { The date under which the product or service was returned to the custom- } \\
\text { er, after reparation. }\end{array}$ \\
\hline Event description & A description of the type of defect detected in the product or service. \\
\hline Seller description & A description of the seller. \\
\hline Additional information & Additional information such as warranties or recipes. \\
\hline
\end{tabular}

The computational construction implements three main functionalities: (1) it allows the user to manage his/her personal information (e.g., contact information, address); (2) it permits the user to consult the solutions of previous cases, and (3) it lets the user to fill in a new case. When filling in a new case, the user can do it in two different ways, depending on whether he/she wants to simulate a given defect on a product or service he/she is considering buying, or there is an actual defect with a product that he/she has already bought. The table depicted below denotes the information that may be necessary for filling in a new case. Note that not all the information is mandatory, depending on the type of the request.

When a request is sent to the server, the agents build a new solution. Once again, depending on the type of the request, the solution is provided in two different ways. If the user is simply simulating an eventual malfunctioning (the simplest case), the solution is provided right away by the agents and shown on the mobile device. If, on the other hand, the user is looking at a solution in a case which may involve access to more multifaceted structured data, the solution is not provided in a hurry, once it must be validated by a human expert, as detailed in [6], i.e., the solution will be available later, after validation. Thus, the user can access it through the mobile device or through the web site. 


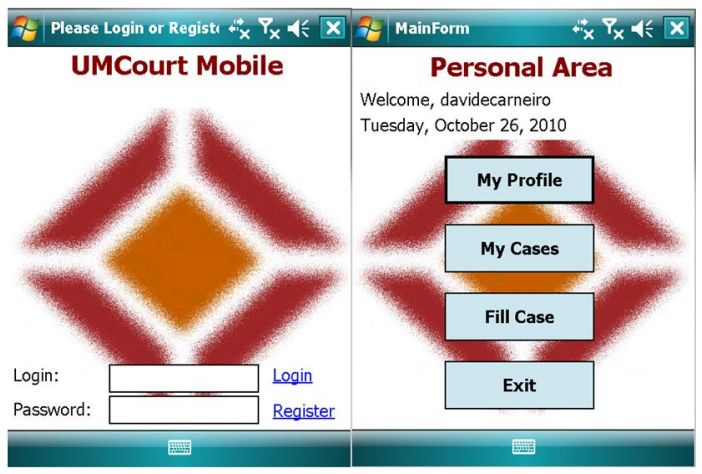

Fig. 2. The login interface and the application main menu.

\subsection{A Scenario}

In order to highlight the main functionality of the application being developed so far, let us consider an example, as it is tinted on Figures 3 and 4; i.e., John, an English citizen, recently moved to Portugal for a few months and bought a PDA for domestic/private use. The contract that was celebrated is of buy/sell type. October $22^{\text {nd }}, 2010$, was the product delivery date. John finds a defect on October $26^{\text {th }}, 2010$, and wants to guess the possible outcome if he decides to deliver the PDA to repair and/or substitution on October $30^{\text {th }}, 2010$. As evidence, John uploads a warranty and a receipt, relative to the dates mentioned above. Concerning the defect, the buyer claims that the product does not fully comply with what was advertised (e.g., the seller said that the PDA has a GPS receiver, but it does not appear to be working). The supplier acts within the range of his/her professional skills and he/she is the producer of the artifact.

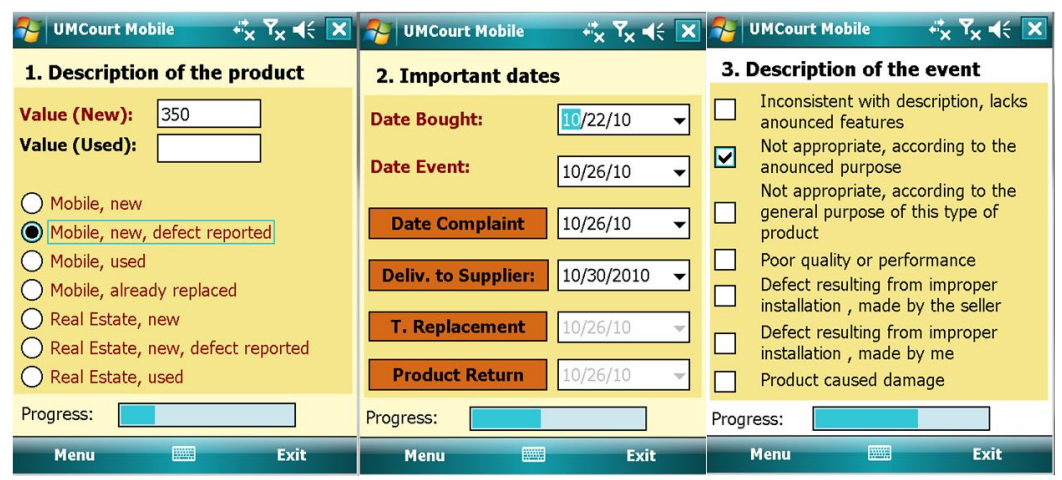

Fig. 3. The first three instances of the interface used for filling in a new case. 
When the customer demands an explanation, there is some extra data that must be taken into consideration, namely his/her name and/or e-mail address, obtained on or after the system, and his/her current location, acquired from the mobile operator. An XML file is then created that includes all the information so far attained which is stored in the user device (Figure 5). This, in turn, is received by the server, which analysis all the legal time-frames that apply in such a particular case (i.e., the software agents make sure that the legal time-frames are under the warranty time-frame (11 days), that the limit of two months counted up since the date of the defect detection has been respected (7 days), and that less than two years passed since the date of the complaint). As the product was delivered for repair and/or substitution and all the legal time-frames have been respected, John is informed that the supplier has two choices: either repair the product in 30 days (at most) at no cost or to proceed to the replacement of the product by an equivalent one (Figure 5). At this moment, John is aware of his rights regarding the current matter, according to the legal system of the country he is currently on.

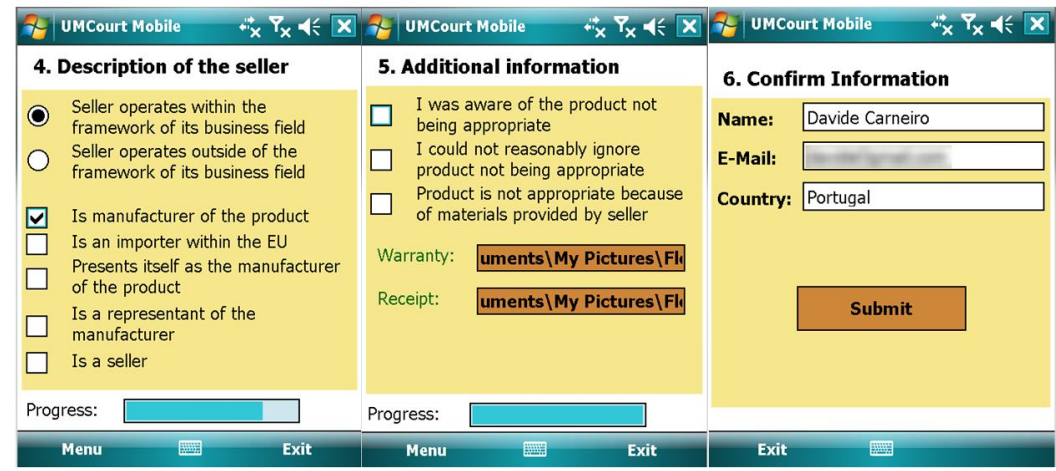

Fig. 4. The last three instances of the interface used for filling in a new case.

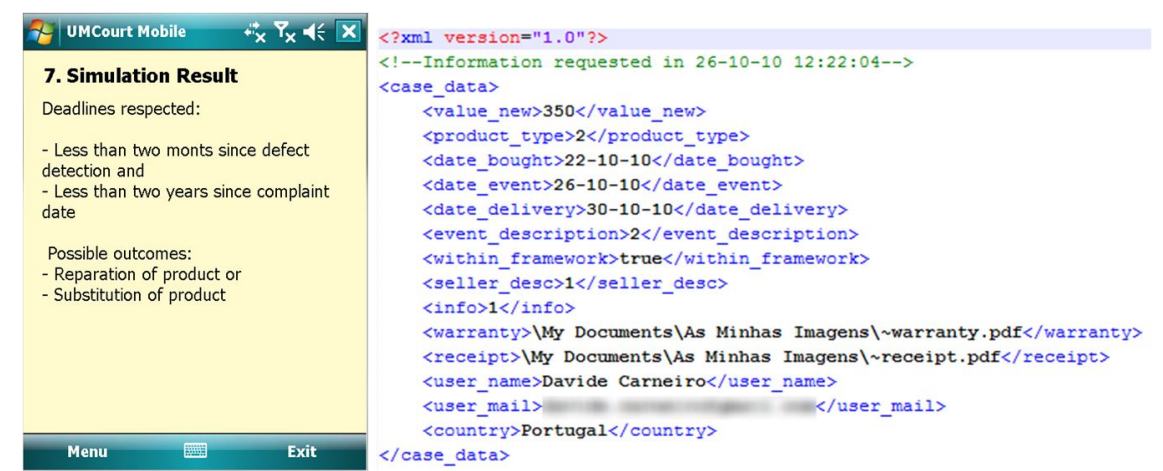

Fig. 5. A snapshot of an interface showing the result of the simulation and the XML file corresponding to the scenario considered. 


\section{Conclusions}

As it has been seen in previous work, in general, rule-based systems are ideal to be used in definite legal domains, such as The Commercial Law. Indeed, a rule-based ODR system was extended under this setting, with a mobile tool that allows the user to access it, independently of his/her location. Moreover, this tool adapts the solutions provided according to the local legal system. What is proposed is a shift from a paradigm in which the user has to explicitly interact with an ODR tool in a specific manner, to a paradigm in which the ODR tool is always available to the user, independently of his/her location. Moreover, such tool adapts its response according to the user location. Thus, we can now speak of virtual environments for dispute resolution, empowered by mobile devices that will significantly improve and personalize access to The Law.

Acknowledgments. The work described in this paper was developed under the TIARAC - Telematics and Artificial Intelligence in Alternative Conflict Resolution Project (PTDC/JUR/71354/2006), which is a research project supported by FCT (Science \& Technology Foundation), Portugal.

\section{References}

1. Raiffa, H.: The Art and Science of Negotiation. Harvard University Press. (2002)

2. Brown, H., Marriott, A.: ADR Principles and Practice. Sweet and Maxwell. (1999)

3. Bennett, S. C.: Arbitration: essential concepts. ALM Publishing. (2002)

4. Katsch, E., Rifkin, J.: Online dispute resolution - resolving conflicts in cyberspace. Jossey-Bass Wiley Company, San Francisco. (2001)

5. Lodder, A., Thiessen, E.: The role of artificial intelligence in online dispute resolution. In Workshop on Online Dispute Resolution at the International Conference on Artificial Intelligence and Law, Edinburgh, UK. (2003)

6. Costa, N., Carneiro, D., Novais, P., Andrade, F.: An Agent-based Approach to Consumer's Law Dispute Resolution. Proceedings of the 12th International Conference on Enterprise Information Systems - ICEIS 2010. (2010)

7. Weiss, G.: Multiagent Systems: A Modern Approach to Distributed Artificial Intelligence. The MIT Press. (2000)

8. Almeida, T.: Lei de defesa do consumidor anotada, Instituto do consumidor, Lisboa (in portuguese). (2001)

9. Almeida, C. F.: Direito do Consumo. Almedina. Coimbra (in portuguese). (2005)

10. Wooldrige, M.: An Introduction to Multiagent Systems, John Wiley \& Sons. (2002)

11. Bellifemine, F. L., Caire, G., Greenwood, D.: Developing Multi-Agent Systems with JADE. Wiley. (2007)

12. Augusto, J.C., Nakashima, H., Aghajan, H.: Handbook on Ambient Intelligence and Smart Environments: a state of the art. Springer Verlag. (2009)

13. Carneiro D., Novais P., Costa R., Neves J.: Developing Intelligent Environments with OSGi and JADE, The Third IFIP International Conference on Artificial Intelligence in Theory and Practice (IFIP AI 2010) Brisbane, Australia. (2010)

14. Mehrabian, A.: Silent Messages - A Wealth of Information about Nonverbal Communication. Personality \& Emotion Tests \& Software. Los Angeles. (2009) 